\title{
Archaeal and bacterial thermostable amylopullulanases: characteristic features and biotechnological applications
}

https://doi.org/10.1515/amylase-2018-0006

Received August 14, 2018; accepted December 30, 2018

\begin{abstract}
Amylopullulanases are endoacting bifunctional enzymes capable of hydrolyzing $\alpha-1,4$ - and $\alpha$-1,6-glycosidic linkages in starch, amylose, pullulan, amylopectin and related oligosaccharides. These enzymes possess single or dual active site(s) for cleaving $\alpha-1,4-$ and $\alpha$-1,6-glycosidic bonds; the former are called amylopullulanases, and the latter, $\alpha$-amylase-pullulanases. These are grouped into GH13 and GH57 families based on the architecture of the catalytic domain and the number of conserved sequence regions. The amylopullulanases/ $\alpha$-amylasepullulanases are produced by bacteria as well as archaea, and among them, thermophilic and hyperthermophilic species are the major producers. The thermostable amylopullulanases find application in one-step starch liquefaction-saccharification to form various sugar syrups and maltooligosaccharides. The starch saccharification process catalysed by amylopullulanases minimizes the use of other amylolytic enzymes, like $\alpha$-amylase and glucoamylase, thereby reducing the cost of sugar syrups. The enzymes also find applications in bread making as an anti-stale and as a detergent additive.
\end{abstract}

Keywords: amylopullulanase; $\alpha$-amylase-pullulanase; starch saccharification; anti-stale; maltooligosaccharides

Abbreviations: CSR, conserved sequence region; DP, degree of polymerization; FnIII, fibronectin type III domain; GH, glycoside hydrolase; SBD, starch binding domain.

\footnotetext{
*Corresponding author: Tulasi Satyanarayana, Division of Biological Science \& Engineering, Netaji Subhas University of Technology, Azad Hind Fauj Marg, Sector 3, Dwarka, New Delhi - 110078, India; E-mail: tsnarayana@gmail.com

Mohanan Nisha, Department of Biosystems Engineering, University of Manitoba, Winnipeg, MB R3T 5V6, Canada
}

\section{Introduction}

Amylopullulanases or $\alpha$-amylase-pullulanases form a class of endo-acting debranching enzymes of the glycoside hydrolases (GHs) included in the sequencebased classification of Carbohydrate-Active enZymes, the CAZy database [1]. The amylopullulanase is a bifunctional enzyme, which cleaves both $\alpha-1,4-$ and $\alpha-1,6$-glycosidic linkages in starch, amylose, amylopectin, glycogen, pullulan and related oligosaccharides [2-5]. They hydrolyze $\alpha-1,4-$ glycosidic linkages in amylose to form products with degree of polymerization (DP) 2-4, while pullulan is generally cleaved at $\alpha-1,6$ - linkages with release of maltotriose. The enzymes are multi-domain proteins having two or three catalytic residues depending of the respective GH family [3,4]. They are grouped into family GH13 or GH57 based on the architecture of the catalytic domain and the number of conserved sequence regions (CSRs) [5-8]. The amylopullulanases of GH13 family possess six or seven CSRs in the catalytic domain, which is folded into a $(\beta / \alpha)_{8}$ or TIM barrel [named after triose phosphate isomerase, the first enzyme discovered to have a $(\beta / \alpha)_{8}$ fold] and the catalytically important amino acid residues, i.e. aspartate (catalytic nucleophile), glutamate (proton donor) and aspartate (transition-state stabilizer) present on the strands $\beta 4, \beta 5$ and $\beta 7$, respectively $[2,3]$. While the GH57 family enzymes possessing five CSRs fold into a $(\beta / \alpha)_{7}$ (i.e. an incomplete TIM barrel), with the catalytic machinery formed by glutamate (catalytic nucleophile) on strand $\beta 4$ and aspartate (proton donor) on $\beta 7[9,10]$. The amylopullulanases from mesophiles belong to GH13 family, while the thermostable amylopullulanases belong to either GH57 or GH13 family [10]. The enzymes of both families employ the retaining mechanism of enzyme action.

Based on the number of active sites within the protein, the enzymes are categorized into two subgroups: the enzymes which possess two active sites occupying separate catalytic domains for cleaving $\alpha-1,4-$ and $\alpha-1,6-$ glycosidic bonds are termed $\alpha$-amylase-pullulanases, 
while amylopullulanases possess a single active site for hydrolyzing both $\alpha-1,4-$ and $\alpha-1,6-$ glycosidic linkages. Amylopullulanases from thermophilic anaerobes possess single active site [12-14], while those from aerobic microbes have either one $[15,16]$ or two active sites for cleaving the $\alpha-1,4$ - and $\alpha$-1,6-glycosidic linkages [17,18].

Amylopullulanases find potential applications in starch saccharification for making sugar syrups, as antistale in bread and other bakery products, and as an additive in detergents [19]. In the conventional process of starch saccharification, $30-35 \%$ of dry starch slurry is gelatinized (at $\sim 60$ to $90{ }^{\circ} \mathrm{C}$ ) to disrupt the structure of the starch granules followed by subsequent liquefaction at $95-105{ }^{\circ} \mathrm{C}(\mathrm{pH}$ 6.5) by bacterial $\alpha$-amylase to dextrins. The dextrins are subsequently saccharified by amylolytic enzymes, like pullulanase, $\beta$-amylase and glucoamylase leading to release of glucose [20]. The $\alpha$-amylases currently employed in the starch conversion process are active at $95^{\circ} \mathrm{C}$ and $\mathrm{pH} 6.8$, and are $\mathrm{Ca}^{2+}$-dependent. The process, therefore, requires the addition of $\mathrm{Ca}^{2+}$ that inhibits glucose isomerase used in the isomerization of glucose to fructose and can also lead to the formation of calcium oxalate, which clogs heat exchangers and pipes over time [21]. The removal of $\mathrm{Ca}^{2+}$ from the product streams by ion exchangers adds to the cost of the process and the final product. Moreover, the pH of the starch slurry (pH 4.5) [22] needs to be raised to 6.8 , and the reversion products, such as isomaltose and maltose formed by glucoamylase at the cost of glucose needs to be minimized. The thermostable and $\mathrm{Ca}^{2+}$-independent amylopullulanases would prove advantageous in the starch conversion process, as it allows increasing substrate concentration, reduces the reaction time, increases maltose and limits the use of glucoamylase, thereby making the process economical [4]. Owing to high thermostability, the amylopullulanases from thermophilic microorganisms of the genus Geobacillus act as efficient biocatalysts for one-step starch liquefaction-saccharification. The advances in molecular biology and protein engineering have led to improvement in enzyme titers, thermostability as well as catalytic activity enabling their efficient use in various industrial processes [23]. This review focuses on the developments in production, molecular aspects, characteristics, protein engineering and applications of amylopullulanases.

\section{Bacterial and archaeal amylopullulanases}

Amylopullulanase is produced by both aerobic as well as anaerobic bacteria, and archaea (Fig. 1), the anaerobic bacteria being the highest producers [12]. Among aerobes, amylopullulanasesareproducedbycertainspeciesofBacillus and Geobacillus, most of which are thermophilic. Bacillus sp. KSM-1378 [24], Bacillus sp. XAL 601 [25], Bacillus sp. TS-23 [26], Bacillus sp. 3183 [27], Bacillus sp. US149 [28], Bacillus subtilis [29], Bacillus sp. DSM 405 [30], Bacillus circulans F-2 [31-33], Geobacillus thermoleovorans NP33 [34], Geobacillus stearothermophilus L14 [35] and Cohnella sp. [36] have been reported to produce amylopullulanases (Table 1). Among thermophilic anaerobes, Thermoanaerobium brockii [12], Clostridium sp. strain EM1 (now Thermoanaerobacterium thermosulfurogenes) [37], Thermoanaerobacter ethanolicus 39E [38], Thermoanaerobium Tok6-B1 [39,40], Thermoanaerobacterium thermosaccharolyticum [41], Thermoanaerobacter finni [42], Thermobacteroides acetoethylicus [42, 43] and Thermotoga maritima [44] are reported as producers of amylopullulanases. Hyperthermophilic archaea Pyrococcus furiosus [45,46], Pyrococcus woesei [47], Thermococcus litoralis [46], Thermococcus celer [48], Thermococcus hydrothermalis [49,50] and Thermococcus profundus [51] produce highly thermostable amylopullulanases (Table 1) belonging to the family GH57 [5,9].

\section{Native amylopullulanases of the genus Geobacillus: production and characteristics}

Among Geobacillus species, amylopullulanases have been produced using G. thermoleovorans NP33 [34] and G. stearothermophilus L14 [35]. Thermophiles, in general, have been reported to produce low biomass and enzyme titres, thus demand optimization of various cultural parameters [19]. Various physical and chemical parameters (temperature, $\mathrm{pH}$, dissolved oxygen, agitation, carbon and nitrogen sources) have been optimized for increasing the biomass and enzyme production. These parameters have been shown to influence the growth as well as enzyme production.

G.thermoleovorans NP33 [34] and G.stearothermophilus L14 [35] produce amylopullulanases in the temperature range between 45 and $80{ }^{\circ} \mathrm{C}$. The impact of temperature on the enzyme production is related to the growth of the organism. Amylopullulanase is maximally produced by $G$. thermoleovorans NP33 in the late exponential growth phase, at $70{ }^{\circ} \mathrm{C}, \mathrm{pH} 7.0$, and $200 \mathrm{rpm}$ [34]. Starch and ammonium sulphate supported maximum enzyme production. The enzyme synthesis by the strain is partially inducible. A low basal level of constitutive enzyme 


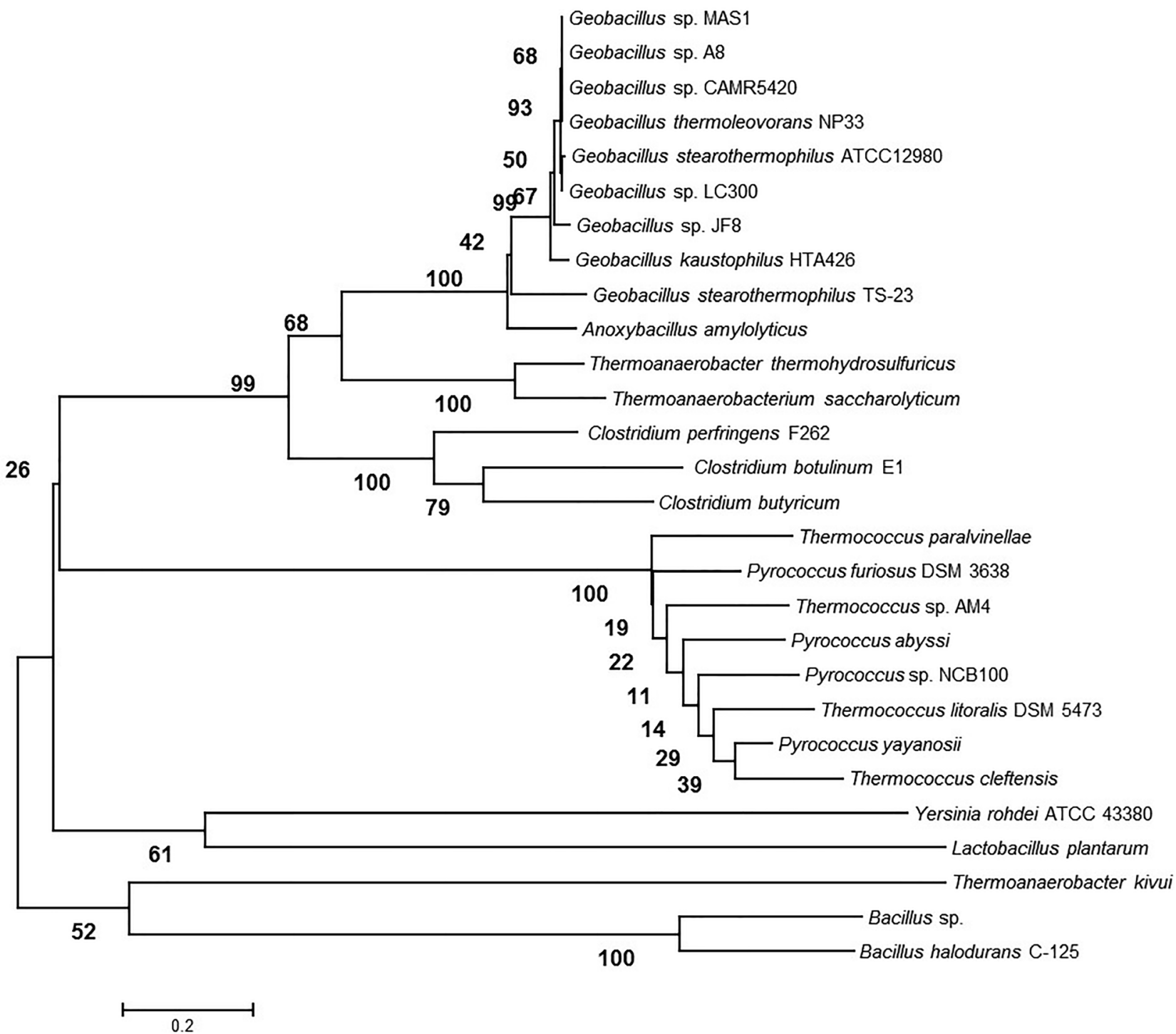

Figure 1. Neighbour-joining tree showing the phylogenetic relationship of the amylopullulanases from bacteria and archaea based on their amino acid sequences. GenBank gi: Geobacillus sp. MAS1, 559464335; Geobacillus sp. A8, 1408737936; Geobacillus sp. CAMR5420, 635250714; Geobacillus thermoleovorans NP33, 386276905; Geobacillus stearothermophilus ATCC12980, 88193077; Geobacillus sp. LC300, 909996913; Geobacillus sp. JF8, 752598410; Geobacillus kaustophilus HTA426, 56381557; Geobacillus stearothermophilus TS-23, 12006232; Anoxybacillus amylolyticus, 1024279633; Thermoanaerobacter thermohydrosulfuricus, 144720; Thermoanaerobacterium saccharolyticum, 237688402; Clostridium perfringens F262, 380306416; Clostridium butyricum, 758313218; Thermococcus paralvinellae, 573025504; Pyrococcus furiosus, 2435438; Thermococcus sp. AM4, 345650580; Pyrococcus abyssi, 499169028; Pyroccus sp. NCB100, 1001992508; Thermococcus litoralis DSM 5473, 374743225; Yersinia rohdei ATCC 43380, 238709313; Lactobacillus plantarum, 161085685; Thermoanaerobacter kivui, 694167291; Bacillus sp. NFR08, 1434604948; Bacillus halodurans C-125, 10176321. Amylopullulanases from Geobacillus thermoleovorans NP33 [49], Geobacillus stearothermophilus TS-23 [50], Thermoanaerobacterium saccharolyticum [4], Pyrococcus furiosus DSM 3638 [40,42], Thermococcus litoralis DSM 5473 [42], Lctobacillus plantarum [27] and Bacillus sp. [13] have been experimentally characterized.

degrades exogenous substrate resulting in low-molecular weight products, which enter the cells and induce enzyme synthesis. There is no requirement for additional trace elements [34]. Batch fermentation in the laboratory fermenter led to two-fold increase in amylopullulanase production by $G$. thermoleovorans NP33 as compared to that attained in shake flasks [34]. The strain has been shown to possess multiple amylopullulanases [46]. The amylopullulanase of $G$. thermoleovorans NP33 (apu105) had a molecular mass of $105 \mathrm{kDa}$, while the molecular mass of G. stearothermophilus L14 amylopullulanase was $100 \mathrm{kDa}$. The amylopullulanase of $\mathrm{G}$. thermoleovorans NP33 (apu105) [52] is highly thermostable with optimum activity at $80{ }^{\circ} \mathrm{C}$ and $\mathrm{pH} 7.0$, while $65{ }^{\circ} \mathrm{C}$ and $\mathrm{pH} 5.5$ are 
Table 1. Characteristics of bacterial and archaeal amylopullulanases. $a$

\begin{tabular}{|c|c|c|c|c|}
\hline Source & Mw & pH & Temp. & Ref. \\
\hline \multicolumn{5}{|l|}{ Mesophilic bacteria } \\
\hline Bacillus sp. KSM-1378 & 210 & 10 & 50 & 24 \\
\hline Bacillus circulans F-2 & 220 & $7-8.5$ & 50 & $31-33$ \\
\hline Bacillus subtilis & 450 & 7.0 & 30 & 37 \\
\hline \multicolumn{5}{|l|}{ Thermophilic bacteria } \\
\hline Bacillus sp. US149 & 200 & 5.0 & 60 & 28 \\
\hline Bacillus sp. 3183 & - & 5.0 & 62 & 27 \\
\hline Bacillus sp. TS-23 & 140 & 9.0 & 55 & 26 \\
\hline Bacillus sp. DSM 405 & 126 & $6.0-6.5$ & 70 & 30 \\
\hline Bacillus sp XAL 601 & 224 & 9.0 & 70 & 25 \\
\hline Clostridium sp. strain EM1 & - & 5.9 & 60 & 37 \\
\hline Cohnella sp. A10 & 70 & 6.0 & 60 & 36 \\
\hline Desulfucoccus mucosus & 74 & 5.8 & 85 & 48 \\
\hline Geobacillus thermoleovorans NP33 & - & 7.0 & 80 & 34 \\
\hline Geobacillus stearothermophilus L14 & 100 & 5.5 & 65 & 35 \\
\hline Thermoanaerobium brockii & 105 & - & - & 12 \\
\hline Thermoanaerobium Tok6-B1 & 120 & 5.6 & 70 & 39,40 \\
\hline Thermoanaerobacterium thermosaccharolyticum & 150 & $5.0-5.5$ & 65 & 41 \\
\hline Thermoanaerobacter strain B6A & 450 & 5.0 & 75 & 101 \\
\hline Thermoanaerobacter ethanolicus 39E & 133 & 5.5 & & 38 \\
\hline Thermobacteroides acetoethylicus & - & $5.0-6.0$ & 75 & 42,43 \\
\hline Thermoanaerobacter finni & - & $5.0-6.0$ & 75 & 42 \\
\hline Thermotoga maritima & 96 & - & - & 44 \\
\hline \multicolumn{5}{|l|}{ Hyperthermophilic archaea } \\
\hline Desulfurococcus amylolyticus JCM9188 & 71 & 5.0 & 95 & 63 \\
\hline Pyrococcus furiosus & 89 & 5.5 & 110 & 45,46 \\
\hline Pyrococcus woesei & 90 & 6.0 & 100 & 47 \\
\hline Thermococcus litoralis & 119 & 5.5 & 110 & 46 \\
\hline Thermococcus hydrothermalis & 128 & 5.5 & 95 & 49,50 \\
\hline Thermococcus profundus & 43 & 5.5 & $80-90$ & 51 \\
\hline Thermococcus celer & - & $5.5-6.0$ & 90 & 48 \\
\hline Thermofilum pendens & 65 & 3.5 & $95-100$ & 102 \\
\hline
\end{tabular}

a Mw, molecular weight $(\mathrm{kDa}) ; \mathrm{pH}, \mathrm{pH}$ optimum; Temp., optimal temperature for activity $\left({ }^{\circ} \mathrm{C}\right)$; Ref, reference $(\mathrm{s})$.

optima for that of G. stearothermophilus L14 [35]. The enzyme possesses single active site for hydrolyzing both $\alpha-1,4-$ and $\alpha-1,6$-glycosidic linkages in soluble and raw starches, pullulan, and malto-oligosaccharides, and it does not hydrolyse panose and cyclodextrins. The action of amylopullulanase from $G$. thermoleovorans NP33 [46] and G. stearothermophilus L14 [35] on different substrates released glucose, maltose, and maltotriose as major end products. Similar findings have been recorded in the amylopullulanase of Anoxybacillus sp. SK3-4 [53]. Amylopullulanases, in general, cleave pullulan to form maltotriose as the only product $[3,35,49,55]$. The enzyme exhibits $\mathrm{Ca}^{2+}$-independency, stability over acidic $\mathrm{pH}$ and the ability to degrade raw starches, the characteristics 
which are highly valued in the starch saccharification process [21].

\section{Cloning, expression and characteristics of recombinant amylopullulanases}

As the levels of production and the specific activity of the amylopullulanases achieved with the wild bacterial and archaeal strains are very low, cloning of the enzyme encoding genes and their expression in heterologous hosts have opened up gateways for improving the protein yield. The genes encoding amylopullulanase are found in Geobacillus sp. MAS1 (GenBank Acc. No.: ESU72863.1), Geobacillussp.A8(EQB96130.1), Geobacillus sp.CAMR5420 (KDE46452.1), Geobacillus sp. LC300 (WP050367846.1), G. kaustophilus HTA426 (BAD77465.1), Geobacillus sp. JF8 (WP_041267797.1), G. stearothermophilus ATCC12980 (KOR93301.1), G. stearothermophilus TS-23 (WP_061567453.1) and G. thermoleovorans NP33 (AFI70750.1). Molecular biology and recombinant DNA technology are of considerable importance for not only enhancing enzyme production, but also improving the efficiency in industrial starch saccharification process [4]. The thermostable proteins cloned and expressed in mesophilic hosts have been shown to display proper secondary structure and sustain their stability at high temperatures, resistance to host proteolysis and simplify the purification by thermal precipitation.

The amylopullulanases from $G$. thermoleovorans NP33 (Gt-apu) [3] and G. stearothermophilus TS-23 [56] with a molecular mass of $182 \mathrm{kDa}$ and $220 \mathrm{kDa}$, respectively, have been cloned and expressed in $E$. coli. In E. coli, the recombinant amylopullulanase of $G$. thermoleovorans NP33 was located in the intracellular fraction, while in the case of G. stearothermophilus TS-23, the intracellular, extracellular and periplasmic fractions contained recombinant amylopullulanase, with major portion being in the extracellular pool. The recombinant amylopullulanase of $G$. thermoleovorans NP33 is optimally active at $60{ }^{\circ} \mathrm{C}$ and $\mathrm{pH} 7.0$ [3]. The enzyme has a single active site for both $\alpha$-amylase and pullulanase activities, based on the kinetics with competing substrates (starch and pullulan) and response to inhibitors. The enzyme forms products with DP 2-4 upon hydrolysis of soluble and raw starches, amylose, amylopectin and related oligosaccharides, with maltopentaose being the smallest substrate to be acted upon by the enzyme. The amylopullulanases of Anoxybacillus sp. SK3-4 [53] and
G. stearothermophilus L14 [56] hydrolyze pullulan to glucose. The amylopullulanase of $G$. thermoleovorans NP33 hydrolyses pullulan to maltotriose, but does not hydrolyze panose and cyclodextrins. The high-molecular weight amylopullulanase of $G$. thermoleovorans NP33 exhibits high thermostability, $\mathrm{Ca}^{2+}$-independency and raw starch degrading activity, as recorded for the native amylopullulanase (apu105). The $\alpha$-amylase and pullulanase activities have been stimulated by $\mathrm{Zn}^{2+}$, while $\mathrm{Hg}^{2+}$ and $\mathrm{Cu}^{2+}, \mathrm{N}$-bromosuccinimide and 1-ethyl-3-(3dimethylaminopropyl)-carbodiimide inhibit the activity.

The protein engineering efforts to truncate the $\mathrm{N}$ and C-terminal portions (Gt-apu $\Delta \mathrm{N} 1$ and Gt-apu $\Delta \mathrm{C}$ ) of the enzyme $[3,57]$ resulted in improved thermostability and specific enzyme activity in comparison with the native enzyme (Gt-apu). A relative decrease in the starch adsorption and saccharification rates of Gt-apu $\Delta \mathrm{N} 1$ suggested the role of the $\mathrm{N}$-terminus ( $\mathrm{N} 1$ domain of Gt-apu that comprises two copies of the X25 module) in raw starch binding. The $\mathrm{N} 1$ truncation has also resulted in significant changes with respect to the substrate specificity of the enzyme. The Gt-apu $\Delta \mathrm{N} 1$ displayed high hydrolytic action on pullulan over starch and hydrolysed maltotetraose as the smallest substrate as opposed to maltopentaose for Gt-apu and Gt-apu $\Delta \mathrm{C}$. The thermodynamic parameters for enzyme deactivation and the structure-function study using far-UV circular dichroism spectroscopy, intrinsic fluorescence emission and aniline-naphthalene-sulphonic-acid fluorescence spectroscopy revealed enhanced conformational and thermal stability of the truncated variants of Gt-apu (Gt-apu $\Delta \mathrm{N} 1$ and Gt-apu $\Delta \mathrm{C}$ ). The thermostability of the enzymes is correlated with low number of cysteine residues [54,58] and disulphide bridges [59]. The heavily glycosylated Gt-apu $\Delta \mathrm{C}$ secreted from the recombinant Pichia pastoris displayed higher thermostability and starch saccharification efficiency than that expressed in E. coli. Moreover, the post-translational modification of the enzyme secreted by $P$. pastoris resulted in altered substrate specificity that hydrolysed maltotriose and maltotetraose unlike that produced in E. coli [60].

The recombinant amylopullulanase encoding gene from G. stearothermophilus TS-23 [56] expressed in E. coli was found to be degenerated, as suggested by zymogram analysis with more than six specific bands of the $\alpha$-amylase activity on polyacrylamide agarose gel electrophoresis. The molecular mass of the largest polypeptide was 220 $\mathrm{kDa}$, while the smallest was of $105 \mathrm{kDa}$. The degeneracy may have been the result of degradation of the newly synthesized polypeptides and/or from incomplete translation. 


\section{Structure of amylopullulanases and role of different domains in catalysis}

The amylopullulanases have been classified in families GH13 and GH57 on the basis of the architecture of catalytic domain and the number of CSRs $[8,61]$. The GH13 family enzymes fold into a catalytic $(\beta / \alpha)_{8}$-barrel with catalytic machinery consisting of $\beta 4$-aspartate (catalytic nucleophile), $\beta 5$-glutamate (proton donor) and $\beta 7$-aspartate (transition-state stabilizer) and have four to seven CSRs [5-7]. These possess [3] the N-domain classified as the family carbohydrate binding module (CBM) 34, the catalytic $(\beta / \alpha)_{8}$-barrel (i.e. TIM-barrel) fold succeeding by the $\alpha$-amylase-type $\mathrm{C}$-terminal domain (AamyC), fibronectin type III domain (FnIII), CBM20 domain, and in some cases, also the S-layer homology domain (Fig. 2a).
The GH57 family enzymes adopt a $(\beta / \alpha)_{7}$ TIM barrel (i.e., an incomplete TIM barrel) and the catalytic machinery encompasses the strand $\beta 4$-glutamate (catalytic nucleophile) and $\beta 7$-aspartate (proton donor) and five conserved sequences [5,61]. The GH57 amylopullulanases, in general, possess [5,9,45,49,62] a signal peptide preceding the catalytic domain, N-terminal glycoside hydrolase family 57 catalytic domain and, two surface layer homology (SLH) like domains and a threonine-rich region in the C-terminal region (Fig. 2b). The GH13 includes all the amylopullulanases from mesophiles, while the thermostable amylopullulanases are grouped into either GH57 or GH13 family. Both families GH57 and GH13, however, are similar in having the same retaining reaction mechanism [63-65]. Many members of the GH13 family have been assigned to subfamilies in 2006 [11]. The characteristics of the amylopullulanases of GH13 subfamilies are listed in Table 2.

a.

\section{G. thermoleovorans NP33 (1655 amino acids)}

G. stearothermophilus TS-23 (2018 amino acids)

\section{G. kaustophilus HTA426 (1588 amino acids)}
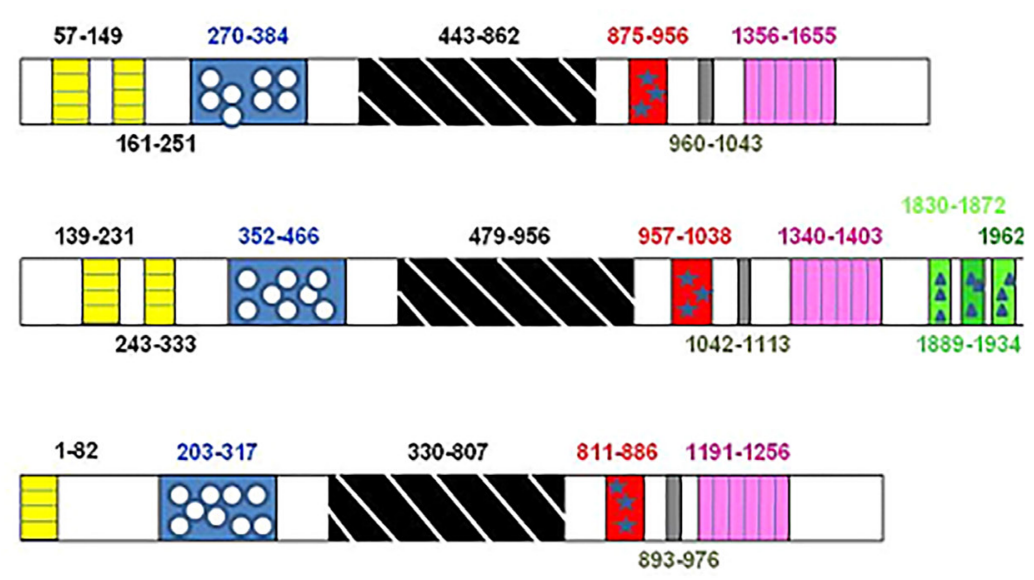

b.

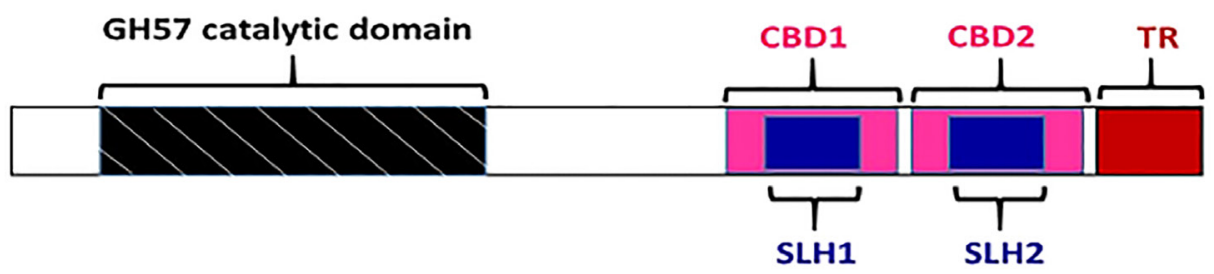

Figure 2. (a) Schematic representation of the conserved domain structure in GH13 amylopullulanases of the thermophilic Geobacillus species, G. thermoleovorans NP33 (UniProt Acc. No.: I1WWV6), G. stearothermophilus TS-23 (Q9EZZ4) and G. kaustophilus HTA426 (Q5KV21). Symbols are as follows: horizontal lines, X25 domain; white dotted box, CBM34; diagonal lines, catalytic domain; starred box, AmyC domain; grey box, fibronectin type III domain; vertical lines, CBM20 domain; boxes with triangles, S-layer homology domain. (b) Putative multidomain structure of GH57 amylopullulanases, in general. GH57, catalytic domain; SLH1 and SLH2, two repeats of surface layer homology motif bearing domain; TR, a threonine rich region. 
Table 2. Characteristics of amylopullulanases belonging to different $\mathrm{GH} 13$ subfamilies. $a$

\begin{tabular}{|c|c|c|c|c|c|c|c|c|}
\hline GH13 & Source & GenBank & Mw & $\mathrm{pH}$ & Temp. & CBM family & Activity & Ref. \\
\hline \multirow[t]{2}{*}{12} & Streptococcus suis $\mathrm{P} 1 / 7$ & CAR47543.1 & 230 & - & - & CBM41 & dual & 103 \\
\hline & Uncultured bacterium & AGL50935.1 & 168 & 9.0 & 40 & CBM41, CBM48 & dual & 104 \\
\hline \multirow[t]{2}{*}{14} & Anoxybacillus sp. & ARM71174.1 & 225 & 7.5 & 60 & CBM20 & single & 53 \\
\hline & Bifidobacterium breve UCC2003 & AAY89038.1 & 182 & - & - & CBM48, CBM25 & dual & 105 \\
\hline 20 & Lactobacillus amylophilus DSM 20533 & APT18553.1 & 90 & 6.5 & 37 & CBM48 & single & 33 \\
\hline 28 & Uncultured bacterium & AGL50935.1 & 168 & 9.0 & 40 & CBM41, CBM48 & dual & 104 \\
\hline \multirow[t]{4}{*}{39} & Geobacillus thermoleovorans NP33 & AFI70750.1 & 182 & 7.0 & 60 & CBM20 & single & 3 \\
\hline & Geobacillus stearothermophilus TS-23 & AAG44799.1 & 223 & - & - & CBM20 & single & 56 \\
\hline & Lactobacillus paracasei B41 & ADK95117.1 & 67 & 5.0 & 45 & - & single & 106 \\
\hline & Thermoanaerobacterium saccharolyticum NTOU1 & ACR15165.1 & $\sim 184$ & $5.0-6.0$ & 70 & CBM20 & single & 107 \\
\hline 41 & Streptococcus suis $\mathrm{P} 1 / 7$ & CAR47543.1 & 230 & - & - & CBM41 & dual & 103 \\
\hline
\end{tabular}

$a$ GH13, GH13 subfamily; GenBank, GenBank accession No.; Mw, molecular weight (kDa); pH, pH optimum; Temp., optimal temperature for activity $\left({ }^{\circ} \mathrm{C}\right)$; Activity, number of catalytic domain for $\alpha$-amylase and pullulanase activities; Ref, reference(s).

\section{$5.1 \mathrm{~N}$-domain}

The amylopullulanases of the genus Geobacillus are known to possess an additional region of around 350 amino acids in the $\mathrm{N}$-terminus relative to $\alpha$-amylases. The N-terminus of the $G$. thermoleovorans NP33 amylopullulanase has $\mathrm{N} 1$ and $\mathrm{N} 2$ domains, the latter has been designated as the CBM34. The N1 domain (57-149 and 161-251 amino acids) is composed of two copies of X25 domain, which has been shown to play a role in the raw starch adsorption and hydrolysis [57]. The important role of these auxiliary domains is to bind polysaccharides and bring the enzyme into close vicinity with its substrate for carbohydrate hydrolysis [66]. The region is homologous to the X25 domain of unknown function, present in the X45 domain of Bacillus acidopullulyticus pullulanase [67]. The N-terminal domain of amylopullulanases does not form a part of the active site in contrast to that reported for isoamylase [68]. The sequence alignment of the $\mathrm{N} 1$ domain of Gt-apu with CBM20 of gt-apu, CBM48 of the $\alpha$-amylasepullulanase of Bacillus sp. XAL601 and the CBM69 of AmyP [69-71] has helped in identifying the amino acid residues of the starch-binding sites 1 and 2. The homology model of $G$. thermoleovorans NP33 amylopullulanase and its N1 domain built using Thermoactinomyces vulgaris $\alpha$-amylase II (PDB code: 1BVZA) and B. acidopullulyticus pullulanase (PDB code: 2WANA) as templates suggested that the N1 domain (residues 1-257) of Gt-apu is positioned as a flexible region away from the rest of the structure (Fig. 3a). The residues 23-257 of the N1 domain adopt an immunoglobulin-like fold ( $\beta$-sandwich) of FnIII (Fig. 3b).

\subsection{Catalytic domain}

The catalytic domain of the Geobacillus amylopullulanases, as those of other enzymes of the $\alpha$-amylase family GH13, has domain A, i.e. the $(\beta / \alpha)_{8}$-barrel, and domain B. The parallel $\beta$-strands are surrounded by $\alpha$-helices [72].

The $\alpha$-amylase family GH13 members are characterized by the presence of 6-7 CSRs (CSR I to VII) [72,73] located on the strands $\beta 3, \beta 4, \beta 5, \beta 7, \beta 2, \beta 8$ and on loop 3 , near the $\mathrm{C}$-terminus of domain $\mathrm{B}$ (Fig. 4). The loop 3 protruding from the catalytic $(\beta / \alpha)_{8}$-barrel domain interconnects the strand $\beta 3$ with the third $\alpha$-helix and, in fact, represents the domain $\mathrm{B}$. It contains the CSR-V, which is differentiated by the calcium binding aspartate residue. The catalytically important amino acids -aspartate (catalytic nucleophile), glutamate (proton donor) and aspartate (transitionstate stabilizer) - are located on the strands $\beta 4, \beta 5$ and $\beta 7$, respectively, of the catalytic $(\beta / \alpha)_{8}$-barrel. The CSR-VI on strand $\beta-2$ is characterized by the presence of the conserved glycine residue separated from proline by seven amino acid residues. A conserved glycine residue and a proline residue are present at the start of the CSR-VII on $\beta 8$ strand. The $G$. thermoleovorans NP33 amylopullulanase has six conserved regions of the GH13 family around the strands $\beta 2, \beta 3, \beta 4, \beta 5, \beta 7$ and $\beta 8$, as follows: CSR-VI, ${ }^{477}$ GVNTIYLNP ${ }^{485}$; CSR-I, ${ }^{22}$ LDGVFNH $^{535}$; CSR-II, ${ }^{665}$ GWRLDVANE ${ }^{673}$; CSR-III, ${ }^{708}$ EIWD $^{711}$; CSR-IV, ${ }^{768}$ LIGSHD $^{773}$; and CSR-VII, ${ }^{818} \mathrm{GAPTIYYGDE}{ }^{827}$. On the other hand, the amylopullulanases from the family $\mathrm{GH} 57$ possess the $\mathrm{N}$-terminal catalytic domain that folds into an incomplete TIM-barrel, i.e. a seven-stranded $(\beta / \alpha)_{7}$-barrel $[5,7,63]$, 


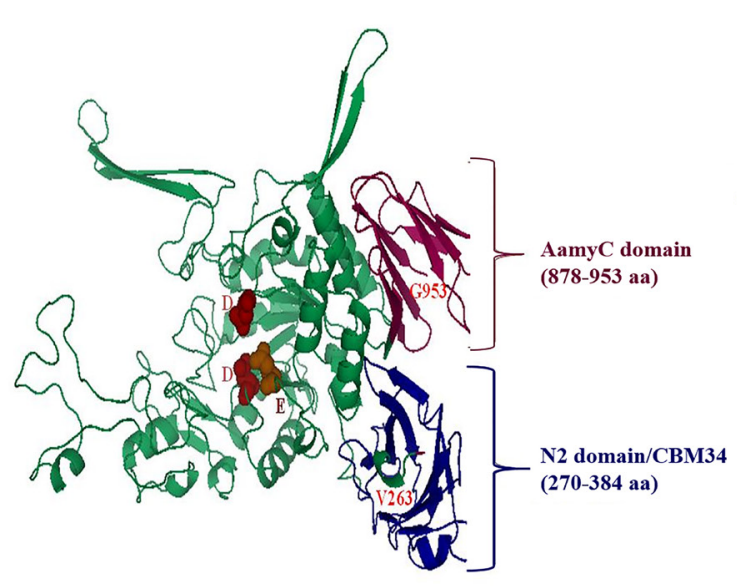

b.

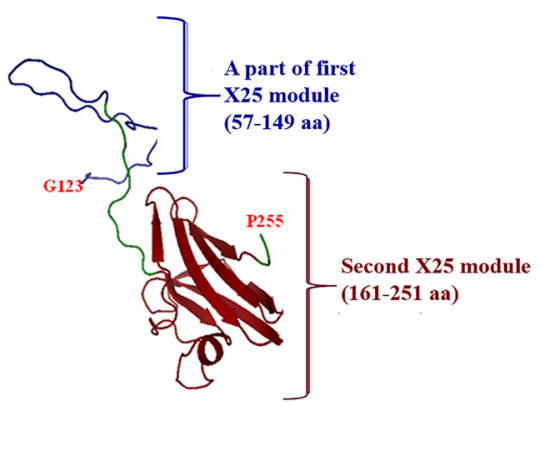

Figure 3. (a) The G. thermoleovorans NP33 amylopullulanase model generated by Swiss-Model (Automated Mode) using Thermoactinomyces vulgaris $\alpha$-amylase II as template. The model is composed of amino acids from V263 to G953 (labelled in red). The domain N2 (CBM34 domain; residues 270-384) and the $\alpha$-amylase domain C (AamyC domain; residues 878-953) are shown in brown and blue colour, respectively. The catalytically important amino acids in the $\alpha$-amylase catalytic domain (residues 397-87), Asp669-Glu708-Asp773, are indicated by spheres. (b) Model of the N1 domain of G. thermoleovorans NP33 amylopullulanase created by Swiss-Model using the pullulanase of $B$. acidopullulyticus as template. The model is composed of amino acids from G123 to P255 (labelled in red). The N1 domain composed of two X25 modules is indicated in different colours - blue depicts a part (residues 123-149) of the first X25 module (residues 57-149), whereas the second X25 module (residues 161-251) is specified by brown.

share five CSRs and their catalytic machinery consists of two residues, glutamic acid (catalytic nucleophile) and aspartic acid (proton donor) at the strands $\beta 4$ and $\beta 7$, respectively [5,7].

\subsection{C-domain}

The C-terminus of G. thermoleovorans NP33 has the domains AamyC, the FnIII domain and CBM20. The AamyC domain is composed of $\beta$-sheets and facilitates proper orientation of the substrate onto the active site [74]; this plays a role in substrate binding site of the catalytic domain in separating $\alpha$-glucan chains of starch and the disruption of the starch granule. The FnIII domain has similar $\beta$-sandwich fold like immunoglobulin domain, and has been reported to play a role in substrate binding [7578]. Highly diverse CBM20s are present in families GH13, GH14, GH15 and GH77 [79]. Starch binding domains (SBDs) constitute a CBM subgroup and assist in starch binding [80]. Currently, SBDs have been found in CBM families $20,21,25,26,34,41,45,48,53,58,68,69$, and 74 , [69,80]. SBDs are usually 100 to 130 amino acids long [69,81] and mainly present in GH13 $\alpha$-amylases, GH14 $\beta$-amylases, GH15 glucoamylases and GH77 amylomaltases [81-83].

The C-terminal region of $G$. stearothermophilus TS-23 possesses nine repeats of the six-amino-acid sequence (Pro-Gly-Ser-Gly-Thr-Thr). The region shares the highest degree of similarity with the Bacillus sp. XAL601 amylopullulanase and is similar to the exoprotein glycinerich repeats (GGXGXD) ${ }_{436}$ of Gram-negative bacteria [84] involved in the secretion of polypeptides [85].

The C-terminal region of GH57 amylopullulanases contains two SLH motif bearing domains and a threoninerich region [49,86] (Fig. 2b).

\section{Applications of amylopullulanases}

\subsection{Starch liquefaction and saccharification}

The global enzyme market was dominated by the food and beverage industry in 2010, with the major market share occupied by the baking enzymes. Starch industry approximately accounts for $15-20 \%$ of the global sales of industrial enzymes. The industrial starch hydrolysis requires action of different endo- and exo-acting enzymes including $\alpha$-amylase, pullulanase, glucoamylase, glucose isomerase, and others. The acid stable, $\mathrm{Ca}^{2+}$-independent and thermostable amylopullulanases from thermophilic microbes, such as Geobacillus spp., have potential application in the starch processing industry as these are thermostable and $\mathrm{Ca}^{2+}$ independent with raw starch degrading ability. Because of the debranching ability and debranching action of the enzymes, thermostable amylopullulanases can be employed as biocatalysts in onestep starch liquefaction-saccharification for producing 

B.breve UC2003
G. thermoleovorans NP33
G. stearothermophilus TS-23

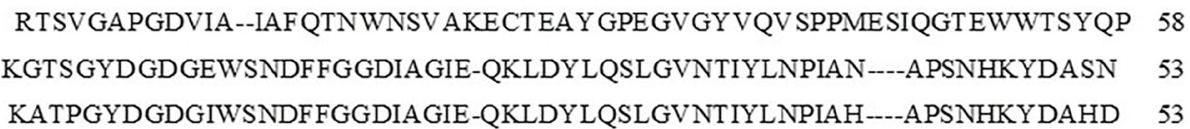

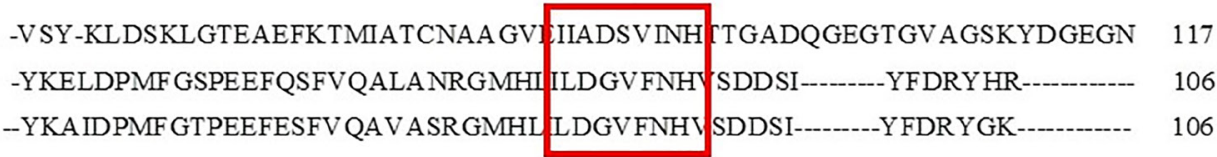

FPAIPYTKENFHDCT KNIGDYTNADEVQNCRLT SLQDLDTSQEYVQDKLADYMNRLLDLG 177 YPTV GAYE--YWEA---VYDLMNEK GLSE---------EEARKQVEEKF---KQEGQTFS-------------- 149

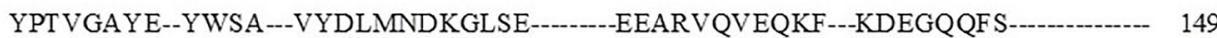

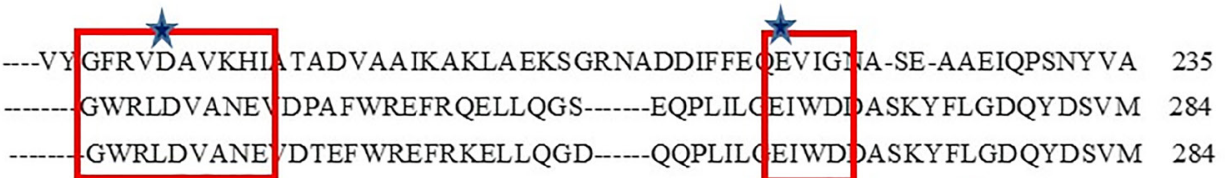

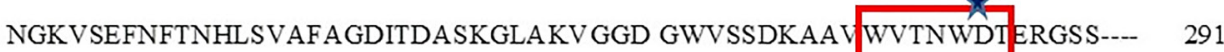
NYR----FRGAVLDFLKNGNAEEADKRLTAIR----ED---YPSEAFYALNINLIGSHDTARAVFL-- 339 NYR---FRGAVLDFLRNGKAEEIDARLTAIR---- ED-YPEEAFYAL INLIGSHD ARAVFL-- 339

IT----Y KKGSKYLLANA FMLA YDY GQPHIY SGYYFDNSDDGAPGATETSVPDMECPT 345 LGNGTDSSERAELDPNYNEELGKKRLKLAVIL QMGY PGAPTIYY GDEAGVTGSRDPDNRRT 393 LGNGTDSYERAELDPNYNEQLGKKRLKLAAILQMGYPGAPTIYYGDEAGVTGSKDPDDRRT 393

\author{
B. breve UC2003 \\ G. thermoleovorans NP33 \\ G. stearothermophilus TS-23
}

\author{
----DGSMT SGTWQCAERWTAIR 364 \\ YPWGKEDQNL LSHYQKVGHIR 420 \\ YPWGSEDTEL IAHYQKVGTVR 420
}

Figure 4. Multiple amino acid sequence alignment of $\alpha$-amylase-type catalytic domains of GH13_14 and GH13_39 amylopullulanases showing the difference in their conserved sequence regions. The amylopullulanase from Bifidobacterium breve UC2003 (UniProt Acc. No.: F9Y041) belongs to the subfamily GH13_14, whereas both Geobacillus thermoleovorans NP33 (I1WWV6) and Geobacillus stearothermophilus TS-23 (Q9EZZ4) amylopullulanases are grouped into the subfamily GH13_39. Four conserved sequence regions are highlighted in boxes and the catalytic triads (Asp-Glu-Asp) are marked with stars. The B. breve UC2003 amlopullulanase possesses two separate catalytic domains specific for $\alpha$-amylase (subfamily GH13_32) and pullulanase (GH13_14) located in the N-terminal and C-terminal parts, respectively, while amlopullulanases of $G$. thermoleovorans NP33 and G. stearothermophilus TS-23 have a single catalytic domain for both $\alpha$-amylase and pullulanase activities.

different sugar syrups by replacing amylolytic enzymes, like glucoamylase and $\alpha$-amylases, thus minimizing the use of glucoamylase by $50 \%$, thereby reducing the total reaction time and the cost of sugar production.

The G. thermoleovorans NP33 amylopullulanase pretreated raw starches have been saccharified to a greater extent by the glucoamylase in comparison to the starch saccharification achieved with the $\alpha$-amylase pre-treated starches and glucoamylase alone [52]. An improved thermostability and catalytic efficiency achieved with the protein engineering effort via C-terminal truncation enabled efficient use of the enzyme in starch saccharification [3].

\subsection{Preparation of maltooligosaccharides}

Maltooligosaccharides are composed of glucopyranosyl units linked by an $\alpha$-1,4-linkages, while the ones containing both $\alpha-1,4-$ and $\alpha-1,6$-glucosidic linkages are called branched oligosaccharides or isomaltooligosaccharides [87]. According to the International Union of Pure and Applied Chemistry, linear maltooligosaccharides are defined as polymers of monosaccharides with DP between 3 and 10. The maltooligosaccharides are widely used in beverage, food and pharmaceutical industries [88]. Maltooligosaccharides are characterized by high 
solubility, less sweetness, low calories, less water activity, good moisture level, acid resistance and heat stability. These can be made into various healthcare and nutritional foods including baby foods, confectionary items, healthcare candies, beverages, healthcare beers and ice creams. Maltotriose, maltotetraose and maltopentaose prevent migration of moisture from starch granules, reduce retrogradation by inhibiting realigning of amylose and amylopectin chains and interfere with starch-gluten interaction; these properties make them useful as antistaling agent in the bread industry [89-91].

Maltooligosaccharide syrups serve as the feed of high nutritiontoinfantsand theaged [92]. Maltooligosaccharides come under soluble non-digestible carbohydrates [93], which stimulate the intestinal microflora, especially the Bifidobacteria and form fermentation products in the colon [30,94]. These non-digestible oligosaccharides are called prebiotics [25], and are categorized as functional food ingredients, which can escape from low-pH stomach fluids and digestive enzymes, and are metabolized in large bowels. Maltooligosaccharides can be gradually absorbed in human body, and thus, provide energy continuously for a long period. Furthermore, maltose and maltooligosaccharides have low calories, thus regulating blood glucose levels, and decreasing post-prandial blood glucose levels [95]. Therefore, it is beneficial for the cardiovascular, diabetes and obese patients. In addition, maltooligosaccharides provide increased body endurance, immunity and induce good therapeutic effect to persons with hypoglycemia and brain disorder associated with overconsumption of energy [96]. Maltooligosaccharides are commercially available as Fuji Oligo syrups, a product of Nihon Shokuhin Kako Kogyo Kabushiki Kasha (Tokyo, Japan).

\subsection{Anti-staling agent in making bread and other bakery products}

The amylopullulanases can be used in the bread industry as an anti-stale. Staling refers to all the undesirable changes, such as loss of the moisture content in the bread crumb, reduced crispness of the crust and diminished bread flavour that occurs upon storage of bread. The $G$. thermoleovorans NP33 amylopullulanase [52] has been reported to act as an anti-stale, which in turn improves the shelf life of bread and other bakery products.

Staling occurs because of retrogradation of the amylopectin of starch [97,98]. An anti-staling agent acts by shortening the amylopectin chain. The $\alpha$-amylase presently used in making bread results in sticky bread when added in excess because of the production of branched maltodextrins [99]. The debranching action of amylopullulanase enables the hydrolysis of the branched maltodextrins, thereby eliminating the stickiness of the $\alpha$-amylase-treated bread and other bakery products [100]. The supplementation of whole wheat dough with the G. thermoleovorans NP33 amylopullulanase markedly improves the quality of the bread by enhancing the shelf-life, texture of bread and the loaf volume [52]. Moreover, maltooligosaccharides generated in the bread by the enzyme action will act as prebiotics in ameliorating human health.

\subsection{Detergent applications}

The alkalitolerant amylopullulanase of G. thermoleovorans NP33 finds application as a detergent additive [52]. The enzyme exhibits significant stability in different commercially available detergents and efficiently removes the starch stain as revealed from the wash performance analysis of the stained cotton fabric. An increase in reflectance when washed with the combination of enzyme and the detergent as compared to the detergent alone suggested the potential use of the enzyme as detergent additive.

\section{Conclusions}

The amylopullulanases have received considerable attention in the past few decades because of their action in cleaving both $\alpha-1,4-$ and $\alpha-1,6$-glycosidic linkages in different complex polysaccharides. The thermostable amylopullulanases from thermophilic bacteria and archaea possess high thermostability, raw starch hydrolysing efficiency and $\mathrm{Ca}^{2+}$ independence. They, therefore, find potential application in the starch processing industry for making maltose and maltooligosaccharide syrups. Because of their action on multiple substrates and debranching action, they can be used for one-step starch liquefaction-saccharification. The multiple amino acid sequence alignment and the domain organization revealed six to seven CSRs of the $\alpha$-amylase family. The protein engineering efforts via truncation enabled to attribute functions to some of the domains, whose functions have not yet been understood, besides improving catalytic activity and thermostability. The limited information available on the three-dimensional structures of amylopullulanases, however, limits our understanding of the structurefunction relationship of the enzymes, which demands further research efforts. 
Conflict of interest: The authors declare no conflict of interests.

\section{References}

[1] Cantarel B.L., Coutinho P.M., Rancurel C., Bernard T., Lombard V., Henrissat B., The Carbohydrate-Active EnZymes database (CAZy): an expert resource for Glycogenomics, Nucleic Acids Res., 2009, 37, D233-D238.

[2] Nisha M., Satyanarayana T., Recombinant bacterial amylopullulanases: developments and perspectives, Bioengineered, 2013, 4, 388-400.

[3] Nisha M., Satyanarayana T., Characterization of recombinant amylopullulanase (gt-apu) and truncated amylopullulanase (gt-apuT) of the extreme thermophile Geobacillus thermoleovorans NP33 and their action in starch saccharification, Appl. Microbiol. Biotechnol., 2013, 97, 6279-6292.

[4] Nisha M., Satyanarayana T., Characteristics, protein engineering and applications of microbial thermostable pullulanases and pullulan hydrolases, Appl. Microbiol. Biotechnol., 2016, 100, 5661-5679.

[5] Janecek S., Amylolytic families of glycoside hydrolases: focus on the family GH-57, Biologia, 2005, 60 (Suppl. 16), 177-184.

[6] Matsuura Y., Kusunoki M., Harada W., Kakudo M., Structure and possible catalytic residues of Taka-amylase A, J. Biochem., 1984, 95, 697-702.

[7] Kuriki T., Imanaka T., The concept of the $\alpha$-amylase family: structural similarity and common catalytic mechanism, J. Biosci. Bioeng., 1999, 87, 557-565.

[8] Janecek S., How many conserved sequence regions are there in the $\alpha$-amylase family? Biologia, 2002, 57 (Suppl. 11), 29-41.

[9] Jiao Y., Wang S., Lv M., Structural and functional analysis of GH57 family thermostable amylopullulanase - a review, Wei Sheng Wu Xue Bao, 2011, 51, 21-28.

[10] Lin H.Y., Chuang H.H., Lin F.P., Biochemical characterization of engineered amylopullulanase from Thermoanaerobacter ethanolicus 39E-implicating the non-necessity of its 100 C-terminal amino acid residues. Extremophiles, 2008, 12, 641-650.

[11] Stam M.R., Danchin E.G., Rancurel C., Coutinho P.M., Henrissat B., Dividing the large glycoside hydrolase family 13 into subfamilies: towards improved functional annotations of $\alpha$-amylase-related proteins. Protein Eng. Des. Sel., 2006, 19, 555-562.

[12] Coleman R.D., Yang S.S., McAlister M.P., Cloning of the debranching-enzyme gene from Thermoanaerobium brockii into Escherichia coli and Bacillus subtilis. J. Bacteriol., 1987, 169, 4302-4307.

[13] Ramesh M.V., Podkovyrov S.M., Lowe S.E., Zeikus, J.G., Cloning and sequencing of the Thermoanaerobacterium saccharolyticum B6A-RI apu gene and purification and characterization of the amylopullulanase from Escherichia coli, Appl. Environ. Microbiol., 1994, 60, 94-101.

[14] Mathupala S.P., Lowe S.E., Podkovyrov S.M., Zeikus J.G., Sequencing of the amylopullulanase $(a p u)$ gene of Thermoanaerobacter ethanolicus $39 \mathrm{E}$, and identification of the active site by site-directed mutagenesis, J. Biol. Chem., 1993, 268, 16332-16344.
[15] Lee S.P., Morikawa M., Takagi M., Imanaka T., Cloning of the aapT gene and characterization of its product, $\alpha$-amylasepullulanase (AapT), from thermophilic and alkaliphilic Bacillus sp. strain XAL601, Appl. Environ. Microbiol., 1994, 60, 3764-3773.

[16] Brunswick J.M., Kelly C.T., Fogarty W.M., The amylopullulanase of Bacillus sp. DSM 405, Appl. Microbiol. Biotechnol., 1999, 51, 170-175.

[17] Hatada Y., Igarashi K., Ozaki K., Ara K., Hitomi J., Kobayashi T., et al., Amino acid sequence and molecular structure of an alkaline amylopullulanase from Bacillus that hydrolyzes $\alpha-1,4$ and $\alpha-1,6$ linkages in polysaccharides at different active sites, J. Biol. Chem., 1996, 271, 24075-24083.

[18] Kim C.H., Kim Y.S., Substrate specificity and detailed characterization of a bifunctional amylase-pullulanase enzyme from Bacillus circulans F-2 having two different active sites on one polypeptide, Eur. J. Biochem., 1995, 227, 687-693.

[19] Nisha M., Satyanarayana T., Thermostable archaeal and bacterial pullulanases and amylopullulanases, pp. 535-587, In: Satyanarayana T., Littlechild J., Kawarabayasi Y. (eds) Thermophilic Microbes in Environmental and Industrial Biotechnology, Springer, New York, 2013.

[20] Hii S.L., Tan J.S., Ling T.C., Ariff A.B., Pullulanase: role in starch hydrolysis and potential industrial applications, Enzyme Res., 2012, 2012, 921362.

[21] Kikani B.A., Singh S.P., The stability and thermodynamic parameters of a very thermostable and calcium-independent $\alpha$-amylase from a newly isolated bacterium, Anoxybacillus beppuensis TSSC-1, Process Biochem., 2012, 47, 1791-1798.

[22] Antranikian G., Microbial degradation of starch, pp. 27-56, In: Winkelmann G. (ed.) Microbial Degradation of Natural Products, Weinheim, 1992.

[23] Nisha M., Satyanarayana T., Characteristics of thermostable amylopullulanase of Geobacillus thermoleovorans and its truncated variants, Int. J. Biol. Macromol., 2015, 76, 279-291.

[24] Ara K., Igarashi K., Saeki K., Ito S., An alkaline amylopullulanase from alkaliphilic Bacillus sp. KSM-1378: kinetic evidence for two independent active sites for the $\alpha-1,4$ and $\alpha-1,6$ hydrolytic reactions, Biosci. Biotechnol. Biochem., 1995, 59, 662-665.

[25] Mussatto S.I., Mancilha I.M., Non-digestible oligosaccharides: a review, Carbohydr. Polym., 2007, 68, 587-597.

[26] Lin L.L., Tsau M.R., Chu W.S., Purification and properties of a $140 \mathrm{kDa}$ amylopullulanase from thermophilic and alkaliphilic from Bacillus sp strain TS-23, Appl. Biochem. Biotechnol., 1996, 24, 101-107.

[27] Shen G.J., Srivastava K.C., Saha B.C., Zeikus J.G., Physiological and enzymatic characterization of a novel pullulan degrading thermophilic Bacillus strain 3183, Appl. Microbiol. Biotechnol., 1990, 33, 340-344.

[28] Roy A., Messaoud E.V., Bejar, S., Isolation and purification of an acidic pullulanase type II from newly isolated Bacillus sp. US149, Enzyme Microb. Technol., 2003, 33, 720-724.

[29] Takasaki Y., Pullulanase-amylase complex enzyme from Bacillus subtilis, Agric. Biol. Chem., 1987, 51, 9-16.

[30] Gibson G.R., Roberfroid M.B., Dietary modulation of the colonic microbiota: introducing the concept of prebiotics, J. Nutr., 1995, $125,1401-1412$. 
[31] Saha B.C., Zeikus J.G., Characterization of pullulanase and $\alpha$-amylase activities of a Thermus sp. AMD33, Trends Biotechnol., 1989, 7, 234-238.

[32] Kim C.H., Kim D.S., Taniguchi H., Maruyama, Y., Purification of a amylase-pullulanase bifunctional enzyme by high-performance size exclusion and hydrophobic-interaction chromatography, J. Chromatogr. A, 1990, 512, 131-137.

[33] Vishnu C., Naveena B.J., Altaf M., Venkateshwar M., Reddy G., Amylopullulanase - a novel enzyme of $L$. amylophilus GV6 in direct fermentation of starch to L (+) lactic acid, Enzyme Microb. Technol., 2006, 38, 545-550.

[34] Noorwez S.M., Ezhilvannan M., Satyanarayana T., Production of a high maltose forming, hyperthermostable and $\mathrm{Ca}^{2+}$ independent amylopullulanase by an extreme thermophile Geobacillus thermoleovorans in submerged fermentation, Indian J. Biotechnol., 2006, 5, 337-345.

[35] Zareian S., Khajeh K., Ranjbar B., Dabirmanesh B., Ghollasi M., Mollania N., Purification and characterization of a novel amylopullulanase that converts pullulan to glucose, maltose, and maltotriose and starch to glucose and maltose, Enzyme Microb. Technol., 2010, 46, 57-63.

[36] Zebardast Roodi F., Aminzadeh S., Farrokhi N., Karkhane A., Haghbeen K., Cohnella amylopullulanases: biochemical characterization of two recombinant thermophilic enzymes, PLoS One, 2017, 12, e0175013.

[37] Antranikian G., Herzberg C., Mayer F., Gottschalk G., Changes in the cell envelope structure of Clostridium sp. strain EM1 during massive production of $\alpha$-amylase and pullulanase, FEMS Microbiol. Lett., 1987, 41, 193-197.

[38] Mathupala S.P., Zeikus J.G., Improved purification and biochemical characterization of extracellular amylopullulanase from Thermoanaerobacter ethanolicus 39E, Appl. Microbiol. Biotechnol., 1993, 39, 487-493.

[39] Plant A.R., Clemens R.M., Daniel R.M., Morgan H.W., Purification and preliminary characterization of an extracellular pullulanase from Thermoanaerobium Tok6-B1, Appl. Microbiol. Biotechnol., 1987, 26, 427-433.

[40] Plant A.R., Clemens R.M., Morgan H.W., Daniel R.M., Active-site and substrate-specificity of Thermoanaerobium Tok6-B1 pullulanase, Biochem. J., 1987, 246, 537-541.

[41] Ganghofner D., Kellermann J., Staudenbauer W.L., Bronnenmeier K., Purification and properties of an amylopullulanase, a glucoamylase, and an $\alpha$-glucosidase in the amylolytic enzyme system of Thermoanaerobacterium thermosaccharolyticum, Biosci. Biotechnol. Biochem., 1998, 62, 302-308.

[42] Koch R., Zablowski P., Antranikian G., Highly active and thermostable amylases and pullulanases from various anaerobes, Appl. Microbiol. Biotechnol., 1987, 27, 192-198.

[43] Koch R., Antranikian G., The action of amylolytic and pullulytic enzymes from various anaerobic thermophiles on linear and branched glucose polymers, Starch/Staerke, 1990, 42, 397-403.

[44] Bibel M., Brettl C., Gosslar U., Kriegshäuser G., Liebl W., Isolation and analysis of genes for amylolytic enzymes of the hyperthermophilic bacterium Thermotoga maritima, FEMS Microbiol. Lett., 1998, 158, 9-15.

[45] Dong G., Vieille C., Zeikus J.G., Cloning, sequencing and expression of the gene encoding amylopullulanase from Pyrococcus furiosus and biochemical characterization of the recombinant enzyme, Appl. Environ. Microbiol., 1997, 63, 3577-3584.

[46] Brown S.H., Kelly R.M., Characterization of amylolytic enzymes, having both $\alpha-1,4$ and $\alpha-1,6$-hydrolytic activity, from the thermophilic archaea Pyrococcus furiosus and Thermococcus litoralis, Appl. Environ. Microbiol., 1993, 59, 2614-2621.

[47] Rüdiger A., Jorgensen P.L., Antranikian G., Isolation and characterization of a heat-stable pullulanase from the hyperthermophilic archaeon Pyrococcus woesei after cloning and expression of its gene in Escherichia coli, Appl. Environ. Microbiol., 1995, 61, 567-575.

[48] Canganella F., Andrade C.M., Antranikian G., Characterization of amylolytic and pullulytic enzymes from thermophilic archaea and from a new Fervidobacterium species, Appl. Microbiol. Biotechnol., 1994, 42, 239-245.

[49] Erra-Pujada M., Debeire P., Duchiron F., O’Donohue M.J., The type II pullulanase of Thermococcus hydrothermalis: molecular characterization of the gene and expression of the catalytic domain, J. Bacteriol., 1999, 181, 3284-3287.

[50] Zona R., Chang-Pi-Hin F., O’Donohue M.J., Janecek S., Bioinformatics of the glycoside hydrolase family 57 and identification of catalytic residues in amylopullulanase from Thermococcus hydrothermalis, Eur. J. Biochem., 2004, 271, 2863-2872.

[51] Kwak Y.S., Akiba T., Kudo T., Purification and characterization of $\alpha$-amylase from hyperthermophilic archaeon Thermococcus profundus, which hydrolyzes both $\alpha-1,4$ and $\alpha-1,6$-glucosidic linkages, J. Ferment. Bioeng., 1998, 86, 363-367.

[52] Nisha M., Satyanarayana T., Characterization and multiple applications of a highly thermostable and $\mathrm{Ca}^{2+}$-independent amylopullulanase of the extreme thermophile Geobacillus thermoleovorans, Appl. Biochem. Biotechnol., 2014, 174, 2594-2615.

[53] Kahar U.M., Chan K.G., Md Salleh M., Hii S.M., Goh K.M., A high molecular-mass Anoxybacillus sp. SK3-4 amylopullulanase: characterization and its relationship in carbohydrate utilization, Int. J. Mol. Sci., 2013, 14, 11302-11318.

[54] Zwickl P., Fabry S., Bogedain C., Haas A., Hensel R., Glyceraldehyde-3-phosphate dehydrogenase from the hyperthermophilic archaebacterium Pyrococcus woesei: characterization of the enzyme, cloning and sequencing of the gene, and expression in Escherichia coli, J. Bacteriol., 1990, 172, 4329-4338.

[55] Kim J.H., Sunako M., Ono H., Murooka Y., Fukusaki E., Yamashita M., Characterization of gene encoding amylopullulanase from plant-originated lactic acid bacterium, Lactobacillus plantarum L137. J. Biosci. Bioeng., 2008, 106, 449-459.

[56] Chen J.T., Chen M.C., Chen L.L., Chu W.S., Structure and expression of an amylopullulanase gene from Bacillus stearothermophilus TS-23, Appl. Biochem. Biotechnol., 2001, 33, 189-199.

[57] Nisha M., Satyanarayana T., The role of N1 domain on the activity, stability, substrate specificity and raw starch binding of amylopullulanase of the extreme thermophile Geobacillus thermoleovorans, Appl. Microbiol. Biotechnol., 2015, 99, 5461-5474.

[58] DiRuggiero J., Robb F.T., Jagus R., Klump H.H., Borgest K.M., Kessel M., et al., Characterization, cloning, and in vitro expression of the extremely thermostable glutamate 
dehydrogenase from the hyperthermophilic archaeon, ES4, J. Biol. Chem., 1993, 268, 17767-17774.

[59] Volkin D.B., Middaugh C.R., The effect of temperature on protein structure pp. 215-247, In: Adhern T.J., Manning M.C. (eds) Stability of Protein Pharmaceuticals, part A. Chemical and Physical Pathways of Protein Degradation, Plenum Press, New York, 1992

[60] Nisha M., Satyanarayana T., Characteristics and applications of recombinant thermostable amylopullulanase of Geobacillus thermoleovorans secreted by Pichia pastoris, Appl. Microbiol. Biotechnol., 2017, 101, 2357-2369.

[61] Martinovicova M., Janecek S., In silico analysis of the $\alpha$-amylase family GH57: eventual subfamilies reflecting enzyme specificities. 3 Biotech, 2018, 8, 307.

[62] Park Y.U., Jung J.H., Seo D.H., Jung D.H., Kim J.H., Seo E.J., et al., GH57 amylopullulanase from Desulfurococcus amylolyticus JCM 9188 can make highly branched cyclodextrin via its transglycosylation activity, Enzyme Microb. Technol., 2018, 114, 15-21.

[63] Naumoff D.G., Hierarchical classification of glycoside hydrolases, Biochemistry (Moscow), 2011, 76, 622-635.

[64] Rye C.S., Withers S.G., Glycosidase mechanisms, Curr. Opin. Chem. Biol., 2000, 4, 573-580.

[65] Ardevol A., Rovira C., Reaction mechanisms in carbohydrate-active enzymes: glycoside hydrolases and glycosyltransferases. Insights from $a b$ initio quantum mechanics/molecular mechanics dynamic simulations, J. Am. Chem. Soc., 2015, 137, 7528-7547.

[66] Guillén D., Sánchez S., Rodríguez-Sanoja R., Carbohydratebinding domains: multiplicity of biological roles, Appl. Microbiol. Biotechnol., 2010, 85, 1241-1249.

[67] Turkenburg J.P., Brzozowski A.M., Svendsen A., Borchert T.V., Davies G.J., Wilson K.S., Structure of a pullulanase from Bacillus acidopullulyticus, Proteins, 2006, 76, 516-519.

[68] Katsuya Y., Maezaki Y., Kubota M., Matsuura Y., Threedimensional structure of Pseudomonas isoamylase at $2.2 \AA$ resolution, J. Mol. Biol., 1998, 281, 885-897.

[69] Peng H., Zheng Y., Chen M., Wang Y., Xiao Y., Gao Y., A starch binding domain identified in $\alpha$-amylase (AmyP) represents a new family of carbohydrate-binding modules that contribute to enzymatic hydrolysis of soluble starch, FEBS Lett., 2014, 588, 1161-1167.

[70] Lei Y., Peng H., Wang Y., Liu Y., Han F., Xiao Y., Gao Y., Preferential and rapid degradation of raw rice starch by an $\alpha$-amylase of glycoside hydrolase subfamily GH13_37, Appl. Microbiol. Biotechnol., 2012, 94, 1577-1584.

[71] Li X., Yu J., Zhang J., Sun H., Zhang X., Backbone and side-chain assignments for a novel CBM69 starch binding domain AmyP-SBD, Biomol. NMR Assign., 2017, 11, 235-237.

[72] MacGregor E.A., Janecek S., Svensson B., Relationships of sequence and structure to specificity in the $\alpha$-amylase family of enzymes, Biochim. Biophys. Acta, 2001, 1546, 1-20.

[73] Takata H., Kuriki T., Okada S., Takesada Y., lizuka M., Minamiura N., et al., Action of neopullulanase: neopullulanase catalyzes both hydrolysis and transglycosylation at $\alpha-(1,4)$. and $\alpha$-(1,6)- glucosidic linkages, J. Biol. Chem., 1992, 267, 18447-18452.

[74] Robert X., Haser R., Gottschalk T.E., Ratajczak F., Driguez H., Svensson B., et al., The structure of barley $\alpha$-amylase isozyme1 reveals a novel role of domain $C$ in substrate recognition and binding: a pair of sugar tongs, Structure, 2003, 11, 973-984.
[75] Suzuki K., Taiyoji M., Sugawara N., Nikaidou N., Henrissat B., Watanabe T., The third chitinase gene (chiC) of Serratia marcescens 2170 and the relationship of its product to other bacterial chitinases, J. Biochem., 1999, 343, 587-596.

[76] Kataeva I.A., Ronald D.S., Ashit S., Larry T.W., Xin-Liang L., Lars G.L., The fibronectin type 3-like repeat from the Clostridium thermocellum cellobiohydrolases $\mathrm{CbhA}$ promotes hydrolysis of cellulose by modifying its surface, Appl. Env. Microbiol., 2002, 68, 4292-4300.

[77] Watanabe T., Ito Y., Yamada T., Hashimoto M., Sekine S., Tanaka H., The roles of C-terminal domain and type III domains of chitinase A1 from Bacillus circulans WL-12 in chitin degradation, J. Bacteriol., 1994, 176, 4465-4472.

[78] Valk V., van der Kaaij R.M., Dijkhuizen L., The evolutionary origin and possible functional roles of FNIII domains in two Microbacterium aurum B8.A granular starch degrading enzymes, and in other carbohydrate acting enzymes, Amylase, 2018, 1, 1-11.

[79] Christiansen C., Abou Hachem M., Janecek S., Viksø-Nielsen A., Blennow A., Svensson B., The carbohydrate-binding module family 20 - diversity, structure, and function, FEBS J., 2009, 276, 5006-5029.

[80] Valk V., Lammerts van Bueren A., van der Kaaij R.M., Dijkhuizen L., Carbohydrate-binding module 74 is a novel starch-binding domain associated with large and multidomain $\alpha$-amylase enzymes, FEBS J., 2016, 283, 2354-2368.

[81] Machovic M., Janecek S., The evolution of putative starchbinding domains, FEBS Lett., 2006, 580, 6349-6356.

[82] Janecek S., Svensson B., MacGregor E.A., Structural and evolutionary aspects of two families of non-catalytic domains present in starch and glycogen binding proteins from microbes, plants and animals, Enzyme Microb. Technol., 2011, 49, 429-440.

[83] Lombard V., Golaconda Ramulu H., Drula E., Coutinho P.M., Henrissat B., The carbohydrate-active enzymes database (CAZy) in 2013, Nucleic Acids Res., 2013, 42, D490-D495.

[84] Welch R.A., Pore-forming cytolysins of Gram-negative bacteria, Mol. Microbiol., 1991, 5, 521-528.

[85] Letoffe S., Wandersman C., Secretion of CyaA-PrtB and HlyA-PrtB fusion proteins in Escherichia coli: involvement of the glycine-rich repeat domain of Erwinia chrysanthemi protease B, J. Bacteriol., 1992, 174, 4920-4927.

[86] Zona R., Janecek S., Relationships between SLH motifs from different glycoside hydrolase families, Biologia, 2005, 60 (Suppl. 16), 115-121.

[87] Casa-Villegas M., Marin-Navarro J., Polaina J., Amylases and related glycoside hydrolases with transglycosylation activity used for the production of isomaltooligosaccharides, Amylase, 2018, 2, 17-29.

[88] Fogarty W.M., Kelly C.T., Recent advances in microbial amylases, pp. 71-132, In: Microbial Enzymes and Biotechnology, Elsevier Science Publishers, London, 1990.

[89] Min B.C., Yoon S.H., Kim J.W., Lee Y.W., Kim Y.B., Park K.H., Cloning of novel maltooligosaccharide-producing amylases as antistaling agents for bread, J. Agric. Food Chem., 1998, 46, 779-782.

[90] Nagarajan D.R., Rajagopalan G., Krishnan C., Purification and characterization of a maltooligosaccharide-forming $\alpha$-amylase from a new Bacillus subtilis KCC103, Appl. Microbiol. Biotechnol., 2006, 73, 591-597. 
[91] Plácido Moore G.R., Rodríguez do Canto L., Amante E.R., Cassava and corn starch in maltodextrin production, Quim Nova, 2005, 28, 596-600.

[92] Stahl B., Alles M.S., Maria B.A., Cereal based infant nutrition with fibre, European Patent EP2124624B1: 2013, 2013.

[93] Roberfroid M., Slavin J., Nondigestible oligosaccharides, Crit. Rev. Food Sci. Nutr., 2000, 40, 461-480.

[94] Nakakuki T., Present status and future of functional oligosaccharide development in Japan, Pure Appl. Chem., 2002, 74, 1245-1251.

[95] Kayode J., Sola A., Adelani A., Adeyinka A., Kolawole O., Bashiru 0., The role of carbohydrate in diabetic nutrition: a review, Internet J. Lab. Med., 2009, 3, 9332.

[96] Zhu A., Romero R., Huang J.-B., Clark A., Petty H.R., Maltooligosaccharides from JEG-3 trophoblast-like cells exhibit immunoregulatory properties, Am. J. Reprod. Immunol., 2011, 65, 54-64.

[97] Kulp K., Ponte J.G., Staling white pan bread: fundamental causes, Crit. Rev. Food Sci. Nutr., 1981, 15, 1-48.

[98] Champenois Y., della Valle G., Planchot V., Buleon A., Colonna P., Influence of $\alpha$-amylases on the bread staling and on retrogradation of wheat starch models, Sci. Aliments, 1999, 19, 471-486.

[99] De Stefanis V.A., Turner E.W., Modified enzyme system to inhibit bread firming method for preparing same and use of same inbread and other bakery products, US Patent US4299848A, 1981: 1981.

[100] Carroll J.O., Boyce C.O.L., Wong T.M., Starace C.A., Bread antistaling method. US Patent US4654216: 1987, 1987.
[101] Saha B.C., Lamed R., Lee C.Y., Mathupala S.P., Zeikus J.G., Characterization of an endo-acting amylopullulanase from Thermoanaerobacter strain B6A, Appl. Environ. Microbiol., 1990, 56, 881-886.

[102] Li X., Zhao J., Fu J., Pan Y., Li D., Sequence analysis and biochemical properties of an acidophilic and hyperthermophilic amylopullulanase from Thermofilum pendens, Int. J. Biol. Macromol., 2018, 114, 235-243.

[103] Ferrando M.L., Fuentes S., de Greeff A., Smith H., Wells J. M., ApuA, a multifunctional $\alpha$-glucan-degrading enzyme of Streptococcus suis, mediates adhesion to porcine epithelium and mucus, Microbiology, 2010, 156, 2818-2828.

[104] Lee Y.S., Seo S.H., Yoon S.H., Kim S.Y., Hahn B.S., Sim J.S., et al., Identification of a novel alkaline amylopullulanase from a gut metagenome of Hermetia illucens, Int. J. Biol. Macromol., 2016, 82, 514-521.

[105] O'Connell Motherway M., Fitzgerald G.F., Neirynck S., Ryan S., Steidler L., van Sinderen D., Characterization of ApuB, an extracellular type II amylopullulanase from Bifidobacterium breve UCC2003, Appl. Env. Microbiol., 2008, 74, 6271-6279.

[106] Petrova P., Petrov K., Direct starch conversion into L-(+)-lactic acid by a novel amylolytic strain of Lactobacillus paracasei B41, Starch/Staerke, 2012, 64, 10-17.

[107] Lin F.P., Ma H.Y., Lin H.J., Liu S.M., Tzou W.S., Biochemical characterization of two truncated forms of amylopullulanase from Thermoanaerobacterium saccharolyticum NTOU1 to identify its enzymatically active region, Appl. Biochem. Biotechnol., 2011, 165, 1047-1056. 